\title{
La sociedad internacional según el liberalismo político
}

\author{
ALFONSO MONSALVE SOLÓRZANO \\ Universidad de Antioquia
}

Es bien sabido que Rawls era consciente de que su teoría del liberalismo político había sido pensada para el ámbito doméstico (salvo un pequeño análisis hecho en Teoria de la Justicia (1971), al que más adelante llegaremos), y considerada válida sólo para Estados democráticos. Por tanto, cra palmaria la necesidad de ampliar su concepción a la sociedad internacional. En The Law of Peoples (1993b) cumple esa tarea.

En ese artículo el objetivo es crear un modelo de consenso político de carácter liberal a nivel internacional que permita la coexistencia de sociedades domésticas con ordenamientos sociales distintos. El procedimiento es proponer un Derecho de Gentes (o Derecho de los Pucblos) razonable -concepto que, por supuesto, igual que el de sociedad bien ordenada por principios de justicia- es una construcción puramente teórica que pretende servir como contraste al derecho internacional realmente existente.

Es, entonces, un proyecto de estirpe kantiana que busca proveer las bases para la convivencia pacífica de la comunidad internacional (ver $1993 \mathrm{~b}$, pp. 54 y 55). Pero también lo es por su método constructivista, que busca producir reglas de justicia que pudieran aceptar todos los Estados que satisfagan las condiciones de ordenamiento interno cimentado en principios liberales de justicia o en concepciones comprehensivas de bien, sobre la base de establecer las condiciones ideales desde las cuales esas reglas puedan tener aceptación universal. Igual que en las sociedades locales, su kantismo metodológico lo lleva a postular, a nivel internacional, la primacía de la justicia sobre el bien, en el sentido de que ninguna concepción de éste puede ser incompatible con los principios que aqućlla fija como reglas de convivencia social.
No obstante, una tarea de esta índole es bastante difícil de realizar:

En primer lugar, existe un problema sobre los presupuestos en los que se sustenta su concepción.

Ia teoría ha de ser suficientemente universal para que no pueda ser acusada de etnocentrismo - un señalamiento muy frecuente, hecho, paradójicamente, en la mayoría de los casos, por filósofos norteoccidentales-, esto es, que pueda ser admitida por todos los Estados del mundo sin que sea percibida como una prolongación del punto de vista de la metafísica propia de Occilente, encarnada para muchos en el discurso individualista de los derechos humanos.

Se trata de un grave obstáculo porque estos derechos están en la base de las intuiciones más importantes de nuestra cultura occidental, por lo que si no los incluye, la teoría no tendría casi ninguna aceptabilidad en Occidente, lo que significaría que no sería suticientemente universal. La solución que adopta Rawls será presentarlos no desde la fuente cultural propia de Occidente, sino desde una perspectiva política que pueda admitir distintas justificaciones. De modo que, semejante a la propuesta de teoría de la justicia doméstica, los principios que ordenan la sociedad internacional han de ser objeto de consenso político entre las distintas concepciones que ordenan los Estados y que se entrecruzan en la arena internacional; será politico sobre reglas de justicia, y no metafísico sobre sus fundamentos morales o éticos.

Pero, por otra parte, si arranca del supuesto de un Derecho de Gentes entre Estados independientes y libres -el correlato del primer principio de justicia doméstico, que supone individuos libres e iguales-como en 
efecto lo hace, es claro que la comunidad internacional sólo puede ser ordenada por principios liberales, pues de lo contrario el supuesto no se podria mantener ${ }^{1}$.

Ahora bien, ordenar la sociedad internacional sobre principios de justicia liberales da por sentada la superioridad de tales postulados sobre otros que, de ser aplicados, producirían ordenamientos alternativos (tales como una sociedad imperial, por ejemplo).

Hay, pues, una petición de principio que puede conducir a una contradicción: no se puede a la vez presuponer que los valores occidentales tales como la igualdad y la independencia sean relativos al ordenamiento de las democracias desarrolladas y luego usarlos para ordenar la sociedad internacional. La peticion de principio consiste, como se sabe, en dar por aceptado lo que precisamente se quiere probar. Si se quiere superar, hay que dar las razones por las cuales se considera que tales valores son preferibles a otros. $\mathrm{Si}$ se trata de una relatividad parcial (que no cubre a todos los valores) ha de argumentarse primero por qué dichos valores podrian generalizarse. En su artículo de 1993 Rawls hace esto únicamente respecto a una versión débil de los derechos humanos. Más adelante volveré sobre este asunto y daré razones a favor de la tesis de adoptar un punto de vista liberal progresista en las relaciones internacionales, pero que procuran superar la petición de principio que surge de la perspectiva rawlsiana.

En segundo lugar, la teoria rawlsiana podría presentar algunos problemas metodológicos:

Es claro, en referencia al primer problema aquí planteado, el de los presupuestos teóricos, que las categorías y los criterios evaluativos para obtener los principios de igualdad como autodeterminación, autodefensa, paz justa y derechos humanos son típicos de la cultura política liberal progresista que surge en la modernidad, de la cual Rawls es uno de sus mejores representantes. En realidad, su constructivismo metodológico kantiano es una forma de expresar los presupuestos de la cultura liberal. Pcro como tal forma especifica de formularlos y dar cuenta de ellos, ha sido sometida a crítica desde otras tradiciones y perspectivas de esa cultura. Aquí se intenta mostrar convergencias, avanzar algunos cuestionamientos y presentar posibles soluciones a los problemas planteados desde una de esas posibles perspectivas.

Una propuesta normativa liberal sobre Derecho de Gentes debe incluir, como ya ha sido planteado, tanto a los pueblos ordenados por principios liberales como a pueblos no ordenados por dichos principios.

La estrategia metodológica de Rawls (1993b, pp. 43-68) para buscar un consenso ideal es aplicar la idea del contrato entre representantes racionales en la posición original y con velo de ignorancia entre ellos como artificio de construcción para obtener los principos de justicia adecuados para la sociedad internacional, utilizada en (1971) para postular los principios que valdrían para una sociedad doméstica, sólo que en esta ocasión los individuos representativos lo son de los distintos pueblos del mundo y no de los grupos sociales de un país.

La sociedad bien ordenada entre pueblos es, así concebida, un modelo que postula un contrato ideal de segundo nivel ${ }^{2}$. Metodológicamente ello significa, entre otras cosas, suponet, en un primer nivel, la existencia de sociedades domésticas bien ordenadas por principios de justicia o por concepciones comprehensivas de bien, y luego extender la analogía constructivista entre éstas y la sociedad de sociedades domésticas.

Este procedimiento implica ya una elección dentro de las opciones constructivistas que Rawls justifica (1993b, p. 50): hubiese podido optar por imaginar un contrato entre los representantes de los distintos grupos representativos de los Estados que cumplen las condiciones de ordenamiento; pero arrancar de las sociedades domésticas como un todo, en primer lugar, de las que están ordenadas por principios liberales, le permite un punto de partida más adecuado porque ya ha establecido sus características esenciales comunes, fácilmente generalizables mediante la extensión del contrato a todas ellas. Pero la razón esencial esgrimida es, en mi criterio, que hay que entender a los pueblos tal como 
ahora existen, es decir, organizados en gobiernos, por lo que «todos los principios y estándares propuestos para el Derecho de los Gentes (de los Pueblos) tienen que, para ser factibles, probar que son aceptables para la opinión pública considerada y reflexiva de los pueblos y sus gobiernos» (ibid., p. 50). $Y$ este argumento está en la línea del pensamiento kantiano de La Paz Perpetua ${ }^{\text {3. }}$.

Previamente, como se dijo más arriba, en (1971, pp. 377-379) ha utilizado el procedimiento del contrato descrito al campo internacional para realizar la justificación de la objeción de conciencia a nivel estatal: dado que ésta es el rechazo a un deber político que podría, entre otros casos, ocurrir frente a una declaración de guerra contra una nación extranjera, reproduce a nivel de las relaciones entre naciones, el contrato con velo de ignorancia para obtener los principios que se generarían en dicha situación original (hipotética).

Rawls plantea alli que el principio básico que se acordaría seria uno de igualdad: todos los países tendrían unos derechos fundamentales iguales, en clara analogía con los derechos iguales de los ciudadanos en el ordenamiento interno. De aquí se derivaria el principio de autodeterminación de los pueblos.

Además, se acordaría el derecho a la autodefensa y a la formación de alianzas para repeler agresiones, en caso de que el derecho se ejerza con causa justa y no se emplee violencia inadmisible contra el contendor, y con el objetivo de conseguir una paz justa. Esto es así porque las personas representativas de Ios Estados en el contrato original hipotético encontrarían que el interés nacional se verá favorecido si éstos actúan de esa manera frente a la guerra, porque una nación justa «no sc mucve por el deseo de poder mundial, o de gloria nacional, ni emprenderá una guerra con el propósito de beneficiarse económicamente $\circ$ adquirir otros territorios. Estos propósitos son contrarios a la concepción de la justicia, que define el interés legítimo de una sociedad a pesar de su preponderancia en la actual conducta real de los Estados* (ibid., p. 379).
Finalmente, se acordaría respetar los tratados en el entendido de que sean compatibles con los otros principios que regirian las relaciones internacionales.

De otra parte, en cambio (1993b, p. 43), lo que Rawls desea en el fondo es establecer los límites de la tolerancia a nivel internacional; es decir, dilucidar los principios y reglas que ha de satisfacer un ordenamiento social, tanto a nivel externo como interno, para que tenga un lugar en la comunidad de naciones, o en otras palabras, lo que razonablemente cabe admitir para que un acuerdo de este tipo permita la coexistencia y la cooperación entre Estados que están ordenados con principios diferentes y hasta incompatibles.

Lo razonable expresa, en este sentido, un mínimo común de reglas de interacción por debajo del cual es inaceptable una forma de ordenamiento estatal. Pero de esto se sigue que las incompatibilidades entre las concepciones que iluminan tales ordenamientos ( $y$ sus prácticas) son de dos tipos: aquellas que presentan un antagonismo tan profundo que no permiten el acuerdo político y esas que, por las razones que sean, lo posibiltan.

La razonabilidad es una condición que fija los parámetros liberales kantianos del acuerdo ${ }^{4}$. Ya en otros trabajos que incluyen a $\mathrm{TeO}-$ ria de la Justicia, pero con especial claridad en Liberalismo Politico (1993a), se define to razonable en relación con lo racional y de ésta resulta la idea metodológica básica de teoría de Justicia como Equidad, pero en general de toda teoria liberal fuerte, de ligar las concepciones comprehensivas de bien a las reglas sociales de interacción de la justicia.

Así (1993a) lo razonable es una condición para el ordenamiento de una sociedad interna y está asentado en características que se predican de los individuos y de sus concepciones. Fn efecto, las personas en una sociedad bien ordenada por principios liberales de justicia son razonables porque están dispuestas a aceptar y proponer criterios equitativos de cooperación social siempre y cuando los otros hagan lo mismo. La razonabilidad está entonces para Rawls incluida dentro de la reciprocidad (pp. 48 y 49 ). Ahora 
bien, lo razonable, para que funcione como un conjunto de reglas de interacción, ha de ser público, y para ello, además de los requisitos de publicidad, ha de ser argumentado aceptando las cargas del juicio y sus consecuencias en el uso de la razón pública (ibid., pp. 54-58).

Lo racional tiene que ver, en cambio, respecto de individuos o colectivos, con las características de juicio $y$ deliberación que los faculta para concebir objetivos e intereses propios y para diseñar y usar inteligentemente los medios y la manera de obtenerlos. Lo racional no excluiria como interés particular el deseo de servir a otros o a un ideal, etc., pero aun en este caso los agentes, que actuaran sólo racionalmente, careccrían de la sensibilidad que lleva a comprometerse con la cooperación equitativa recíproca (ibid., p. 51 ).

Todo ciudadano, afirma Rawls, ticne dos facultades morales: puede tener un sentido de la justicia, lo que significa la capacidad de ser razonable, y puede construirse una concepción del bien, o sea, la capacidad de ser racional. Pero es claro que una concepción de bien no puede ser incompatible con las condiciones de razonabilidad porque impediría la coexistencia social.

Extrayendo conclusiones de las ideas anteriores, Rawls caracteriza una sociedad razonable como aquella en que las partes, independientcmente de las concepciones comprehensivas que profesen, están dispuestas a proponer términos para la cooperación tales que sean aceptables por las otras, de manera que cada una pueda beneficiarse más con los acuerdos obtenidos de to que lo haria sin ellos (ibid., p. 54).

Esa idea de socicdad razonable es la que tiene en mente Rawls cuando piensa en el consenso internacional.

Así como en (1971 y 1993a), en (1993b) ${ }^{5}$ el velo de ignorancia fija condiciones de razonabilidad para el acuerdo originario hipotético de la sociedad internacional porquc ningún representante de un pueblo, actuando como un agente racional, conoce las ventajas económicas, políticas, etc, de los otros ni del que representa.
El primer paso consiste cn extender cl pacto a sociedades bien ordenadas por principios liberales de justicia. Éstas se caracterizan por respetar los derechos y libertades básicas de sus ciudadanos y, en el campo externo, por no ser expansionistas ni practicar guerras de agresión a otros países.

En las condiciones de simetria que el velo de ignorancia garantizaría los representantes de los pueblos, en tanto que estos últimos son libres e iguales, acordarian, entre otros, los siguientes siete principios:

1. La libertad e independencia de cada pueblo ha de ser respetada por los otros.

2. Los pueblos son partes íguales de sus propios acuerdos.

3. Pueden ejercer el derecho a la autodefensa pero no el derecho a la guerra.

4. Han de respetar el deber de no intervención (salvo agresión de Estados «proscritos" o violación grave de los derechos humanos por un Estado a sus miembros).

5. Deben respetan los tratados y compromisos adquiridos.

6. En caso de guerra defensiva cumplen las restricciones establecidas internacionalmente.

7. Respetan los derechos humanos (1993b, p. 55).

El segundo paso en la construcción del pacto es ampliarlo a las sociedades bien ordenadas «jerárquicamente», es decir, aqucllas que se estructuran o están influidas decisivamente por un principio de bien común comprehensivo (religioso o filosófico); no es irrazonable creer que en ellos el sistema jurídico sinceramente se guía por una concepción de justicia o de bien conuún que «tiene en cuenta los intereses esenciales de la gente e impone deberes y obligaciones morales a todos los miembros de su sociedad* (ibid., p. 61), y aunque es claro que no respetan plenamente la libertad de expresión porque privilegian una doctrina comprehensiva ni están organizadas democráticamente, sí reconocen la libertad de conciencia, tienen un cierto grado de consulta jerárquico y permiten el derecho de emigración; es decir, respetan los derechos humanos de su pueblo, 
si bien no a la manera como esto se entiende en Occidente; además, en el plano de las relaciones con otras sociedades son pacíficas y no son ni expansionistas ni agresoras.

Para Rawls la simetría que proporcionaría en la posición original el velo de ignorancia garantizaría la razonabilidad de los representantes de las sociedades jerárquicamente. Elo bastaría para que estuviesen en pie de igualdad frente a los representantes de las sociedades liberales, y por tanto, podrían pactar los siete principios que las sociedades liberales habrian acordado.

Adicionalmente, según Rawls, las dos clases de sociedad coincidirian en respetar los derechos humanos a nivel interno. $Y$ en este punto Rawls intenta defender su universalidad: estos derechos no se generan desde ninguna tradición comprehensiva (en especial de Occidente), sino que son el estándar mínimo de las instituciones políticas bien ordenadas de todos los pueblos.

Peroen tanto que distintos de los derechos fundamentales de las democracias occidentales, y precisamente porque han de entenderse como estándares mínimos, «los requerimientos que producen deberían ser bastante débiles" (1993b, p. 68). Los derechos humanos cubren «los derechos básicos tales como el derecho a la vida y a la seguridad, a la propiedad personal, a los elementos de la regla de derecho, así como el derecho a una cierta libertad de conciencia y de asociación y el derecho a emigrar» (loc. cit).

Estos derechos sitúan los mínimos internos que cualquier sociedad bien establecida debe cumplir porque fijan las condiciones de legitimidad y decencia de un régimen y su orden legal. Su violación reiterada y grave permite excluir justificadamente de la comunidad internacional a los regímenes que los infrinjan, sancionarlos económica e incluso militarmente según sea cl caso, y establecer el límite del pluralisno entre los pueblos (ibid., p. 71).

En conclusión, to razonable a nivel internacional significa para cada Estado aceptar los siete principios entre Estados y respetar los derechos humanos en la versión aquí presentada. Los Estados que no cumplan con estos criterios son «proscritos», en especial si siendo potencias económicas practican la agresión a segundos.

Como puede verse, críticas aparte, la analogía constructivista entre las sociedades de primer nivel y la del segundo permite comprender la propuesta internacional de Rawls. Pero como toda analogia, ésta tiene limitaciones explicativas y además recibe, como ya se dijo, las críticas que han sido formuladas a la teoría de base. La extensión metodológica propuesta implica:

Concebir la sociedad intemacional, ya se ha visto, como un sistema de cooperación equitativa entre pueblos iguales e independientes, ventajosa para todos sus integrantes, de manera similar a como la sociedad doméstica, ordenada por principios tiberales de justicia, sc entiende como un sistema de cooperación equitativa entre individuos libres e iguales.

Siguiendo la analogía, así como el consenso sobrepuesto interno sólo es posible si los individuos gozan de un mínimo de bienestar material y social; así el consenso internacional es posible únicamente entre Estados que han asegurado para sus individuos ese minimo de bienestar.

Aqui encuentro varias dificultades:

Una es el artificio metodológico: el procedimicnto del velo de ignorancia tiene, a este nivel, todos los problemas que se le han senalado entre individuos de una sociedad ${ }^{6}$, con el agravante de que no se trata ya de personas sino de colectividades, en cuyo interior puede haber personas que tienen diferencias esenciales aún sin resolver sobre su comunidad política?

Otra es la concepción de la sociedad doméstica: metodológicamente tampoco es adecuado partir de sociedades cerradas, ordenadas por principios de justicia liberales o por concepciones comprehensivas. La idea de sociedad cerrada implica que actividades como el intercambio económico y cultural son marginales, to cual, evidentemente, no es cierto, porque estamos en una sociedad globalizada en la que hay que postular, entre otras variables, la hegemonia de la economía de mercado, el desarrollo desigual y el mul- 
ticulturalismo. Vivimos en un mundo globalizado fuertemente interdependiente $\mathrm{e}$ inequitativo.

$Y$ es en este contexto donde hay que analizar las consecuencias del pensamiento de Rawls cuando reflexiona sobre las dificultades y soluciones a los problemas de las sociedades que estan en condiciones desfavorables para integrarse al Derecho de los Pueblos. Ellas padecen ala ausencia de tradiciones políticas y culturales, de capital humano y de know how, de recursos materiales y tecnológicos que hacen posible una sociedad bien ordenadas (ibid., p. 74).

Una idea básica de Rawls al respecto es la afirmación de que cada pueblo tiene el derecho de ordenarse por los principios que desee, ya sean éstos liberales o comprehensivos.

Inmediatamente después asevera explícitamente la inaplicabilidad en el campo de las relaciones internacionales de cualquier principio liberal de justicia distributiva que busque ordenar las relaciones entre sociedades, porque éstos sólo son aplicables, en su concepto, a las sociedades democráticas bien ordenadas (ibid., p. 75).

Adicionalmente sostiene que las sociedades bien ordenadas más ricas tienen la obligación de ayudar a los países pobres para que éstos puedan cumplir las condiciones necesarias para ingresar a la comunidad bien ordenada de naciones. Pero la asistencia internacional debe condicionarse al cumplimicnto de los derechos humanos y a la satisfacción de las necesidades básicas de los habitantes de esos Estados.

Pero la tesis crucial al respecto es que la existencia de sociedades que no satisfacen el mínimo de bienestar que se requiere para ingresar a la sociedad bien ordenada de naciones no se debe a la escasez de recursos naturales (la mayoría de los países ricos carecen de ellos) ni tampoco es asunto de condiciones inequitativas de intercambio y de dominación política, sino más bien es un problema generado por las tradiciones culturales y políticas: «Los grandes males sociales en las sociedades más pobres probablemente son los gobicrnos opresivos y las elites corrup- tas, la opresión de las mujeres auspiciada por religiones irrazonables, con el resultado de una superpoblación relativa más allá de lo que la economía puede sostener decentemente. Quiza no haya sociedad alguna en ninguna parte del mundo cuyo pueblo, si está razonable y racionalmente gobernado, y sus miembros ajustados sensiblemente a su economía y recursos, no pudiera tener una vida decente y digna de vivir» (ibid., p. 76).

Esta última visión plantea la tercera dificultad (que se relaciona con la insuficiencia metodológica del velo de ignorancia): en la realidad mundial el proceso de globalización no se caracteriza por ser un sistema de cooperación entre Estados en pic de igualdad, sino por ser fuertemente asimétrico, lo cual produce como resultado una sociedad altamente estratificada. La estratificación no surge espontáneamente, sino que las inequidades fundamentales son de responsabilidad básica a las potencias del primer mundo, al haberlas originado y mantenido con su explotación económica y dominación política y cultural, de donde se sigue que para resolver esencialmente esta situación es urgente que se practique una redistribución de beneficios y cargas a nivel internacional.

Sobre esas premisas destaca la inmensa distancia que separa al liberalismo político internacional de Rawls de la realidad mundial. No por el hecho de proponer un modelo, sino porque el modelo propuesto esconde elementos centrales de la suciedad internacional actual, por lo que la contrastación de ésta con aquél resulta poco esclarecedora: si el problema central - la existencia del binomio dominación-dependencia- no aparece en el modelo, su solución, que es lo que importa, ni siquiera se plantea. Pero si lo sugiriese (el problema), cl cómo solucionarlo -la justicia distributiva- para alcanzar la situación ideal, que de nuevo es lo que importa, no se puede aplicar. Ésa es la lógica de la propuesta de Rawls.

De una parte, para él no existe el problema de la dominación internacional y su correlato la dependencia, con lo que elimina la necesidad de la aplicación de principios de justicia distributiva a nivel mundial. Con esto, de la 
otra, niega la responsabilidad que le compete al primer mundo en la situación de injusticia distributiva a este nivel, achacando el atraso y la miseria de los pueblos del mundo a los gobiernos corruptos, la superpoblación y las discriminaciones ancestrales, como si dichos gobiernos no fuesen casi siempre, por no decir en todos los casos, arropados o colocados desde las metrópolis y como si las medidas económicas y las políticas estatales no fuesen impuestas desde êstas, haciendo uso de todos los medios para ello, incluso el de la agresión militar, impidiendo el desarrollo autónomo (aunque vinculado en condiciones de equidad con otras economías) y generando el atraso. Si se niega esa responsabilidad, las obligaciones morales, políticas y económicas de los paises del primer mundo con los de la periferia se reducen a la asistencia (ayuda) a aquellos pueblos que estén en graves dificultades, es decir, son una acción de caridad.

De lo anterior se sigue que, desde el punto de vista de la sociedad internacional, el primer bien que hay que distribuir es el de la independencia económica y política de los países. $Y$ dentro de ese marco, aplicar principios de justicia distributiva que lleven al desarrollo económico y a la democracia de cada país, para que haya bienes que distribuir y una forma posible de hacerlo equitativamente. A una conclusión como ésta sólo se puede llegar si metodológicamente se parte de considerar el mundo como un todo asimétricamente relacionado.

De ahí que para volver a la crítica sobre la forma de extender el contrato no habría de considerarse un Derecho de Gentes (o de los Pueblos) como un segundo momento luego de haber construido un contrato cn una sociedad cerrada fuertemente. No existe hoy ningún Estado que sea rawlsianamente cerrado. Sus relaciones, su posición en la sociedad internacional habrán de determinar sus obligaciones extemas y la manera de tratar sus obligaciones internas. Por decirlo de alguna manera, dado el lugar que ocupa un país en el concierto mundial, tiene una cuota de responsabilidades con la sociedad internacional. Desde el punto de vista moral, si la riqueza de un país se ha forjado en partc por el tra- bajo, el intercambio desigual y los recursos de otros países, tiene la obligación de cesar en su dominio y explotación, establecer relaciones simetrícas con ellos y ejercer la solidaridad, y a nivel interno reacomodar la economía, las cargas y las oportunidades para que sus nacionales no desmejoren su calidad de vida.

Es que las obligaciones de justicia son distintas a la de la solidaridad caritativa. Como dice acertadamente Beitz, estas obligaciones «podrian requerir también esfuerzos de reforma institucional a gran escala. La retórica de la "Declaración de la Asamblea General sobre el estabecimiento de un Nuevo Orden Económico Internacional" sugiere que ésta es la clase de obligación que exige a los países más ricos incrementar sustancialmente sus contribuciones a los países menos desarrollados y reestructurar radicalmente el sistema económico mundial» (1979, p. 127).

Pero Rawls renuncia a las posibilidades que su propia teoria ofrecía para contribuir a resolver el problema. Ya en (1971, pp. 7, 8 y 457) aseguraba que su teoría de justicia distributiva no era aplicable al ámbito internacional.

En su último trabajo rechaza explícitamente los intentos de Beitz en ese sentido: "Aunque pienso que el principio de diferencia es razonable para la justicia doméstica en una sociedad democrática, no es factible como una vía para tratar el problema general de condiciones desfavorables entre sociedades» (1993b, p. 75). La razón para este rechazo $(1971$, p. 457$)$ estriba en que la teoría de Justicia como Equidad supone, como ya se dijo, que los Estados-nación son cerrados, más o menos autosuficientes, por lo que sólo interactúan de forma marginal, lo cual evidentemente no es cierto en una sociedad globalizada.

Quiero resaltar que habida cuenta de que el sistema económico sobre el que funciona la sociedad internacional actual es la economía de mercado, a la que se le aplican criterios neoliberales, la afimación de Rawls termina justificando esta forma despiadada de explotación a escala global. En efecto, no 
hay principios distributivos distintos en una sociedad de mercado que los que se generan desde ella y que son precisamente los principios de justicia distributiva liberal. Si la sociedad internacional está construida sobre esa cconomía, entonces son ellos los que hay que aplicarle. $Y$ dichos principios prevalecen sobre esa forma de economía si se quiere una sociedad más justa. Porque el modelo económico ha tenido históricamente maneras distintas de manifestarse y la experiencia social ha ido decantando formas de atenuar sus manifestaciones opresivas que incluso permiten el surgimiento de valores sociales de contenido liberador. Como decía el Rawls de 1971, en una sociedad bien ordenada politicamente por principios liberales la justicia prima sobre la eficacia.

No se entiende entonces, para volver al problema incial de los presupuestos de la teoría de Rawls, cómo unos postulados sí son aplicables a la sociedad internacional, los equivalentes al primer principio de su teoria doméstica, pero no los que se derivan del segundo, que tienen que ver con la igualdad de oportunidades y principio de diferencia.

Un mercado mundial ordenado por principios neoliberales no se plantea el problema de la justicia distributiva. No hay en esa concepción algo que se pueda llamar justicia distributiva, como claramente lo señala Nozick (1975) al defender filosóficamente esa concepción económica. Es el modelo que se nos ha impuesto, y las consecuencias no pueden ser más desastrosas para los pobres del mundo, incluidos los de los países metrupolitanos. Quizá la verdadera razón de la negativa de Rawls estriba en que una aplicación a escala internacional de la justicia distributiva implica una reforma a fondo de la manera como actualmente funciona la economía de mercado.

A pesar de lo anterior, la idea de un Derecho de los Pueblos sobre la base de un consenso político internacional y sobre principios liberales es plausible ${ }^{9}$.

El acuerdo político que propone exige la existencia de una entidad supranacional, como la ONU, que haga cumplir el consenso. Los siete principios, que incluyen el de inde- pendencia nacional - relativa a la no viola. ción grave de los derechos humanos de sus habitantes en cada estado-y la exigibilidad del respeto de éstos como fundamento del consenso, no obstante, sólo tendrian sentido si se acompañan:

a) Con un acuerdo sobre justicia distributiva que fije las obligaciones de los países desarrollados en este campo, que conduzca, como ya se dijo, al desarrollo económico independiente de todos los Estados y a la construcción de formas denocráticas de gobierno que permitan una distribución justa a nivel doméstico.

b) La distribución justa implica una ampliación del concepto de derechos humanos para que incorpore además de los derechos civiles los derechos económico-sociales con la fijación de mínimos aceptables y los culturales, así como los de preservación del medio ambiente, en todos los Estados del mundo.

Esto es así porque el listado que hace de los derechos humanos es muy tenue. Su argumento de que son un mínimo $y$, por tanto, distinto al mínimo liberal, tomado en serio, lo llevaría a uno a justificar ol confesionalismo (teocrático o monopartidista), la censura y la autocracia y a ni siquiera pronunciarse sobre los mínimos materiales para llevar una vida digna, esto es, a aceptar la explotación y la opresión despiadadas. Su concepción de los derechos humanos habla del respeto a la vida, pero podría permitir las mutilaciones por razones religiosas; y de una regla de derecho, pero no dice si ésta ha de garantizar la justeza de las causas y la corrección de sus procedimientos.

Por supuesto, es imposible llevar a la práctica el listado completo de derechos de una vez. Para que se pongan en marcha es necesario un doble acuerdo:

Uno a nivel internacional que fije las transferencias económicas, científicas y tecnológicas y de recursos que permitan alcanzar, en plazos determinados, acordados colectivamente, metas de desarrollo económico y de distribución en los distintos países que posibiliten el alcance de estándares interna- 
cionales sobre ingreso, seguridad social, servicios públicos, educación y respeto a la vida, a la integridad personal y otras libertades civiles y políticas y derechos culturales. Asimismo, medidas para la protección del medio ambiente y la vida en la tierra, según las responsabilidades que le competan a cada país.

Otro a nivel nacional, que implica propósitos comunes y formas de gobierno que permitan alcanzar esas metas con una distribucion equitativa y con un creciente respeto a los derechos humanos que se acaban de listar.

Ello supone reformas de los organismos internacionales de decisión como la ONU, el Banco Mundial y el Fondo Monetario Internacional, con el fin de democratizarlos para que sirvan a los intereses de la comunidad internacional y no sólo a los de las naciones del primer mundo, y el cumplimiento de la Declaración de Derechos de 1948, mediante la operatividad de los Pactos de Derechos Civiles y Políticos y de los Derechos Sociales Económicos y Culturales de 1966 , así como el acatamiento verificable de los acuerdos y documentos relativos a los Derechos de la Mujer y a la Declaración de los Derechos del Niño, y a los Protocolos de Ginebra.

El respeto a otras formas de cultura distintas a la occidental no tiene nada que ver con la justificación de prácticas opresivas. El florecimiento de las culturas del mundo sólo scrá posible si se pone en claro qué es lo que en una sociedad globalizada vincula a las sociedades estatales unas con otras, es decir, cuáles son los rasgos universales y/o universalizables que comparten. Y la economía de mercado, junto con los valores encarnados en los derechos humanos, son dos de ellos por razones diferentes pero complementarias. La petición de principio que aparece cuando se quiere evitar el etnocentrismo desaparece cuando se muestra este hecho social mundial.

De un lado, la cconomía de mercado aparece inicialmente por primera vez en Occidente, pero dada su naturaleza expansiva se universaliza.

Del otro, la concepción actual de los derechos humanos está históricamente ligada a ese modelo económico hasta el punto de que su desarrollo y profundización tho puede entenderse sino en relación con la lucha de los oprimidos y los sectores progresistas de la sociedad modema conira las consecuencias nocivas del modelo. Como sintetiza José María González (1989, pp. 181 y ss.) apelando a Weber y Bloch, arrancan legitimando los intereses económicos de la burguesía naciente, afirmando el derecho de propiedad y las condiciones necesarias para que el capital se desarrolle; toman otra perspectiva con la afirmación de los derechos económicos y sociales en los siglos $\mathrm{xIx}$ y $\mathrm{xx}$, en contra incluso de las trabas prácticas y teóricas que este proceso ha contlevado; y continúan con la aparición de nuevas generaciones de derechos en la medida en que la sociedad se globaliza.

De manera que aunque en la historia de distintas culturas se encuentren antecedentes de respeto a ciertos derechos y ejemplos de tolerancia religiosa y hasta política, los dere chos humanos tal y como hoy se conciben son resultado de la modernidad.

Pero su origen no tiene nada que ver con su utilidad. Sì la globalización se entiende, aplicando la teoria de Santos (1995), como un continuo proceso de particularismos que se universalizan exitosamente (tal como la economía de mercado) y de localismos globalizados (tales como los centros de maquila en el Tercer Mundo o el agotamiento de los recursos naturales de sus pueblos), entonces, dado el carácter irreversible de ese modelo económico en el mundo, los derechos humanos habrán de entenderse como un particularismo que hay que universalizar paratelamente a esa economía, pues son la única forma conocida de limitar los efectos destructivos que conlleva la dominación y explotación sobre los que ella descansa. En este sentido, son una conquista de toda la humanidad porque permiten la convivencia pacífica, la cooperación social, la solidaridad y una vida digna para cada ser humano.

Si ello es así, el respeto a las distintas culturas no puede justificar teóricamente la existencia de regímenes autocráticos que a nombre de tradiciones ancestrales basadas en concepciones comprehensivas de tipo religioso 
saquean a sus pueblos, o los torturan y les impiden toda posibilidad de ejercicio democrático. Más si se tiene en cuenta que muchas de ellas se basan en interpretaciones discutibles de sus fuentes sagradas, como en el caso típico del Islarn, en el que hay lecturas y prácticas tolerantes y pluralistas coherentes con su texto sagrado.

El argumento del respeto a otras culturas tampoco puede obviar la estandarización de formas de vida y comportamiento que se derivan de la globalización y socialización de los procesos de producción, gestión y de uso intensivo de ciencia y tecnología como fuerzas productivas de punta que ya Weber describía en su época.

En cambio, hay otra clase de particularismos respecto a valores y prácticas suciales que se universalizan con el propósito de imponer la irracionalidad implicita del sistema económico, o que lo hacen, aprovechando la posición de privilegio en el escenario mundial de ciertas potencias, con el objeto de imponer su estilo de vida y valores culturales especificos. Es el caso del consumismo y la apoliticidad, por un lado, y la identificación con la lengua, patrones estéticos, preferencias raciales, etc., como formas de vida dignos de imitarse en todo el mundo, por el otro, que sicmpre o casi siempre menosprecian o minusvaloran otras formas de vida y de cultura.

\section{BIBLIOGRAFIA}

BerTz, Charles R.: Political theory and international relations, Princeton, New Jersey, Princeton University Press, 1979.

Chauvier, Stéphan: «Libéralisme politique et universalisme juridique. Droit de gens et droits de l'homme selon John Rawls", en Revue de métaphisique et de morale, junio de 1996, núm. 2.

Gonzálrz, José María: «Fundamento de los derechos humanos», en El fundamento de los derechos humanos, Peces-Barba Martinez (ed.), Madrid, Editorial Debate, 1989.
GRAx, John: Enlightenment's wake, Politics and culture at the close of the modern age, Londres/Nueva York, Routledge, 1995, reprinted 1996.

HABERMAS, Jügen: «Reconciliation through the public use of reason: remarks on John Rawls's Political Liberalism", en The Journal of Philosophy, vol. XCII, núm. 3, marzo $1995 \mathrm{a}$.

- «Kants Idee des Ewigen Friedens", en Kritische Justiz, Jahrgang 28, Heft 3, 1995. Traducción en formato electrónico de Juan Carlos Velasco. Citado como $1995 \mathrm{~b}$.

Kant, Inmanuel: La Paz Perpetua, Madrid, Editorial Tecnos, 1985.

- Filosofia de la historia, Fondo de Cultura Económica, 1992.

Monsalve, Alfonso: «a idea del consenso en Rawls. Una exposición crítica», en Liberalismo y comunitarismo. Encuentro en Medellin, Francisco Cortés, Alfonso Monsalve (eds.), Valencia, Ediciones Alfons El Magnànim, 1996.

RawLS John: «Replay to Habermas», en The Joumal of Philosophy, vol. XCII, núm. 3, marzo 1995.

- Political liberalism, Nueva York, Columbia University Press, 1993. En las notas, 1993a.

- "The law of peoples», en On Human Rights, Schute, Stephen \& Hurley, Susan (eds.), Nueva York, The Oxford Ammesty Lectures, Harper Collins Publishers, 1993. En las notas, $1993 \mathrm{~b}$.

- A Theory of Justice, Cambridge Mass., Harvard University Press, 1971.

SANTOS, Boaventura de Sousa: Towards a new common sense: law, science and politics in the paradigmatic transition, Londres/Nucva York, Routledge, 1995.

TAYIOR, Charles: sLiberal politics and Public Sphere", en Philosophical Arguments, Cambridge/Londres, Harvard University Press, 1995.

Thiebaut, Carlos: «Democracia y diferencia: un aspecto del debate sobre el multiculturalismo", en Anales de la catedra Framcisco Suárez, 31 (1994). 


\section{NOTAS}

1 Ver el análisis $S$. Chauvier al repecto (1996, pp. 169.188$)$.

2 De cualquier manera, lo que tiene en mente es un contrato de segundo nivel - cntre Estadosque posteriormente (ver nota 35 de 1993b) puede convertirse en uno de tercero (o más niveles) si se concreta la tendencia de la formación de sociedades interregionales como la Union Europea o la Comunidad de Estados en torno a Rusia. Su visión de futuro es ésta, de grandes federaciones, con organizaciones comp la ONU con la vocería de todas las sociedades del mundo.

${ }^{3}$ Habermas (1995) piensa, por el contrario, que el Estado cosmopolita debería construirse a partir de la reprcsentación individual y propone como primer paso la reforma de ONU, cuya asamblea general deberia estar formada por representantes directos de los individuos de los distintos pueblos del mundo. El argumento básico contra la representación indirceta a través de las Estados es que el presupuesto kantiano de considar al individuo como al depositario de los derechos es contradictorio con el principio de independencia estatal, por lo gue la autonomía individual no debería estar mediada por la soberanía estatal. Desde mi perspectiva, no obstante, el enfoque de Rawls es mucho más viable en las actuales circunstancias.

4 Rawls (1993a, nota 1, pp. 48 y 49) reconoce explicitamente la genealogia de esa idea cn Kant.

5 En la presentación de algunas de las características centrales de la teoría internacional de Rawls sigo, básicamente, lo expuesto en mi artículo aLa iden del consenso en Rawls. Una cxposición críticas (1996).

- Para ilustrar, sólo citaré de manera libre las objeciones de labermas (1995), combinándolas con las mías: el grado de racionalidad pretendido por Rawls, entre hipotéticos sujetos representativos, impide una comprensión completa de la situación de sus representados $y$, por tanto, sus intereses de mâs alto orden (p. 116) y en condiciones de pluralismo social el imponer una perspectiva común a las partes, objetivo del velo de ignotanacia, neutraliza las perspectivas particulares que son las que mutren el discurso ético e imponen su caracter dialógico, csto $\mathrm{cs}$, argumentativo (pp. 117-119). El velo de ignorancia esconderia hechos importantes que deberian tenerse en cuenta pata bacerse una idea suficiente de la situación, habida cucnta de lo decisivo del acuerdo. Piénsese, por ejem. plo, en la explotación económica, la dominación y control politicos, las asimetrías culturales. Este tipo de situaciones solo podrian ser superadas, según Habesmas, mediante el ejercicio de la democracia deliberativa en el que las partes conocen plenamente su situación y la de los otros, y acuerdan un Estado de derecho y unos procedimientos que se aplican para resolver las situaciones de conflicto, siempre con la participación real de los implicados.

${ }^{7}$ El hecho de que Raws plantee la posibilidad de construir un Derecho de los Putblos que incluya sociedades bien ordenadas por principios distintos a los tiberales de la tradición occidental puede reconocerse como una concesión al conunitarismo, resultado de críticas como las de Taylor (1992). Pero, por otro lado, no se sabe qué tipos de sociedades tiene en mente cuando propone el modelo de ordenamiento por concepciones comprehensivas (de la misma mancra que las democracias occidentales del norte sólo están cuasi bien ordenadas por principios liberales de justicia, pero el modelo de ordenamiento liberal se dirige a ellas para perfeccionarlas). Si está considerando algunas como Arabia Saudita, entonces uno no entiende qué clase de derechos humanos garantizan esos países a sus pueblos más allá de la relativa riqueza económica, porque allí lo que existe es una enorme empresa familiar que usa la organización jurídico-político-religiosa del Estado para saquear los inmensos recursos que produce su economia y que niega casi toda clase de dercchos a sus súbditos.

" En su trabajo, ya clásico (1979, pp. 127-176), Beitz critica el escepticismo dominante en la tooría filosófica sobre las telaciones internacionales que suponen todas el catado de naturaleza hobbesiano, to que hace imposible o inútil una teoría normativa a este nivel. Como ejemplo de la viabilidad de una teoria tal, plantea la generalización y aplicación de los dos principios contractualistas de justicia raw/sianos al campo internacional, tomando como caso los recursos naturales y partiendo del principio de que hay una analogia esencial entre las sociedades domésticas y la sociedad mundial en cuanto al problema de distrihuciôn.

" Debo esta postura a Carlos Thiebaut, quien la ha defendido en distintas oportunidades. 


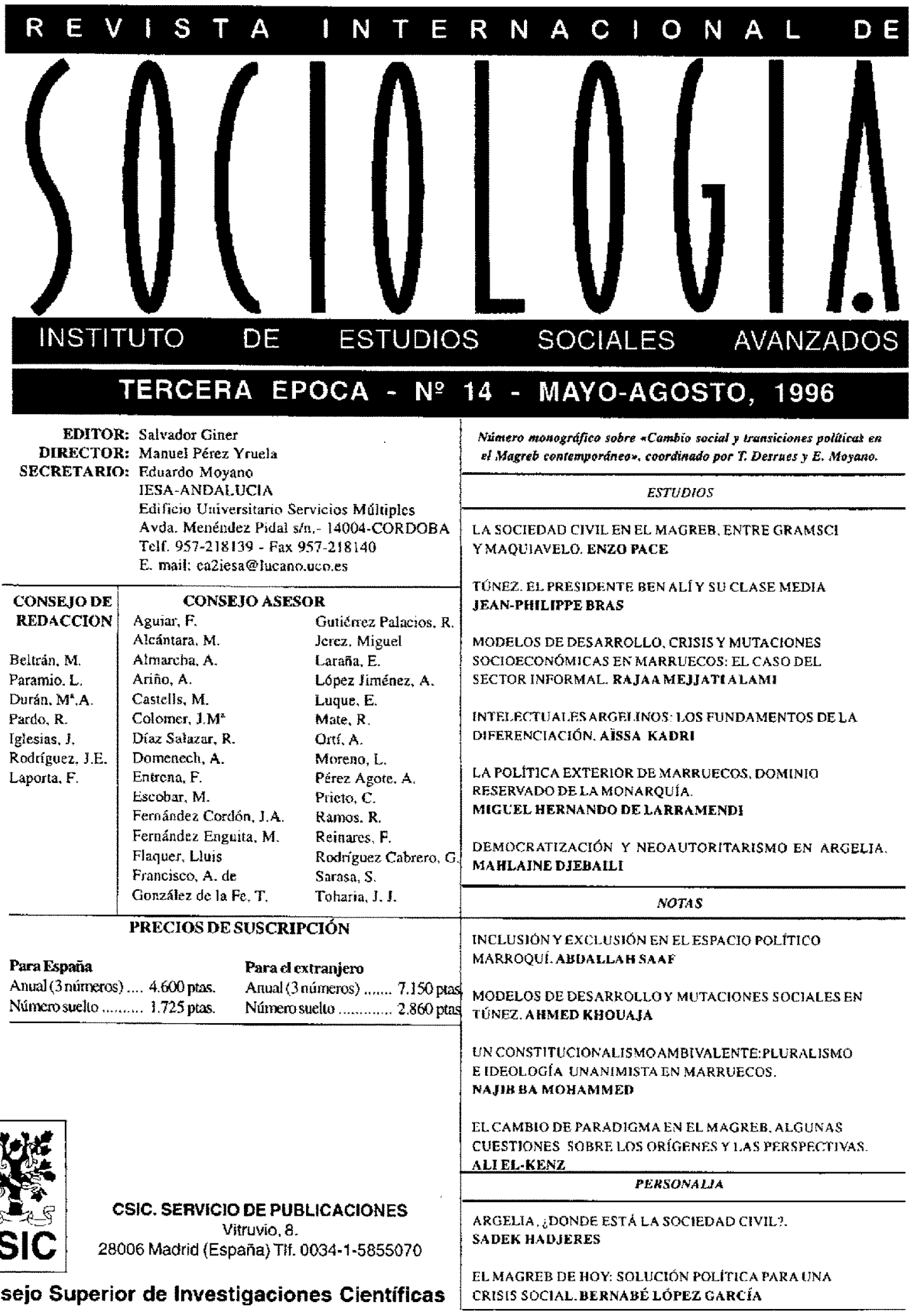

